\title{
The evaluation of microbiology and prognosis of fournier's gangrene in past five years
}

Lap-Ming Tang ${ }^{1}$, Yu-Jang Su ${ }^{1,2^{*}}$ and Yen-Chun Lai ${ }^{3}$

\begin{abstract}
Objectives: Fournier's gangrene (FG) is an devastating disease that affects the perineum and genitourinary region, and is commonly a result of poly-microbial infection. This study is aimed to determine the correlation between micrology and prognosis of FG in the past five years.

Methods: This study was a retrospective cohort study that was designed to study the trends in micrology and prognosis of FG. From the PubMed database, articles published in the recent 5 years (from Jan1 $1^{\text {st }}, 2009$ to Dec $31^{\text {st }}$, 2013) were reviewed. A total of 19 articles (each with $n>30$ and with thorough data descriptions in the topic of Fournier's gangrene), were enrolled in this study. The consolidated data was further analyzed by commercial statistical software (SPSS for Windows).
\end{abstract}

Results: The twenty-two studies have covered FG cases from year 1981 to 2011, with a mean duration of 9.2 years. The total number of cases is 4,365. Majority of the cases are male (84.1\%). The mean age and mortality rate is $51.8 \pm 5$ years old and $11.1 \pm 8.9 \%$, respectivly. The most commonly found pathogen is poly-microbial organism (54\%), followed by Escherichia coli (46.6\%) and Streptococcus (36.8\%). The major risk factors are diabetes (43.7\%), Body mass index of $>30$ (40.7\%), and hypertension (38.1\%). Mortality rate in older patient group (age $>51.8$ years old) is significantly higher than those of the younger group ( $22 \%$ vs. $5.5 \%, p=0.0001)$.

Conclusions: Older patients with genital or perineal pain should be examined for crepitus dermis. When a patient is diagnosed with $\mathrm{FG}$, swift consultation with surgeons and administration of broad-spectrum antibiotics are required in order to save the patient's live.

Keywords: Escherichia coli; Fournier's Gangrene; Microbiology; Poly-microbial; Prognosis

\section{Background}

Fournier's gangrene (FG) is a devastating necrotising disease that affects the perineum and genitourinary regions. The common cause of FG is poly-microbial infections, where the diabetes mellitus is an attributing common risk factor (Shyam and Rapsang 2013). Study has shown that males, especially in their 60 to 70 s, are more often affected by FG when compared to other populations (Rodríguez Alonso et al. 2000). Aside from diabetes, other risk factors of FG also include chronic alcoholism, renal failure, and obesity (Montoya Chinchilla et al. 2009). The majorities of FG studies have shown that

\footnotetext{
* Correspondence: yjsu.md@msa.hinet.net

'Department of Emergency Medicine, Mackay Memorial Hospital, Taipei, Taiwan

${ }^{2}$ Department of Oral Hygiene, College of Oral Medicine, Taipei Medical University, Taipei, Taiwan

Full list of author information is available at the end of the article
}

early diagnosis and aggressive management of FG are required to significantly improve patient outcome. Due to the fact that FG is not a common disease, a prospective study is difficult to perform. Therefore, In this study, a large number of FG cases that have occurred in the past five years are gathered by retrospective literature review and analyzed to determined the relationship between micrology and prognosis of FG.

\section{Methods}

A retrospective cohort study was designed to investigate the correlation between micrology and prognosis of FG. A search from the PubMed database returned a total of 1,015 literatures that contain the keyword "Fournier's gangrene". The resulting literatures were further limited to the literature $s$ that were published within the past 5 years, (from Jan.1, 2009 to Dec 31, 2013), where a total 
of 330 articles remained. The articles that contain case numbers of less than 30 were excluded from the study, since the low sample number cannot establish a normal distribution for the evaluation of statistical significance. In the end, there were 19 articles that was enrolled into this study. The combined data and descriptions of Fournier's gangrene are listed in Table. 1 References (Martinschek et al. 2012) to (Ersoz et al. 2012). These enrolled research literatures are from Germany $(n=4$, $21 \%)$, Turkey $(n=4)$, United States of America $(n=2)$, Pakistan $(n=2)$, Spain $(n=2)$, Mexico $(n=1)$, Brazil $(\mathrm{n}=1)$, Taiwan $(\mathrm{n}=1)$, Tunisia $(\mathrm{n}=1)$ and Croatia $(\mathrm{n}=1)$. The data was analyzed with a commercial statistical software (SPSS for Windows, version 11.0, SPSS Ltd., Chicago, IL). Statistical $\chi 2$ tests were performed and the significance was set at a $\mathrm{p}$ value of less than 0.05 (2-tailed).

\section{Results}

The twenty-two studies have covered FG cases from year 1981 to 2011, with a mean duration of 9.2 years. The total number of cases is 2,656. Majority of cases are male $(84.1 \%)$ and female is accounted for $15.9 \%$.

The mean age of the patients is 51.8 years old, and the average mortality rate is $11.1 \pm 8.9 \%$. When comparing between the older age group (age $>51.8$ years old) and the younger group (age of less or equal to 51.8), the mortality rate was found to be higher in the older group than younger $(22 \pm 8.8 \%$ versus $5.5 \pm 2 \%, p=0.0001)$ The most commonly found pathogen is poly-microbial organism (54\%), followed by Escherichia coli (46.6\%) and Streptococcus (36.8\%). The other contributing pathogens also include Bacteroides, Enterbacter, Staphylococcus, Enterococcus, Pseudomonas, Corynebacterium, and Klebsiella pneumoniae (Figure 1).

The major risk factors for FG are diabetes (43.7\%), body mass index of higher than 30 (40.7\%), and hypertension (38.1\%). Other risk factors also include heart disease (38\%), alcoholism (31.4\%), smoking (22.5\%), renal failure (13.8\%), urethral operation history, neurogenic bladder, and corticosteroid user (Figure 2).

\section{Discussion}

Fournier's gangrene (FG) is a rare emergent condition that affects the perineum and urogenital region. The clinical course of FG is fulminant and serious regardless of parenteral antibiotic treatment. The median time from syptom presentations to skin gangrenous change is 6 days (Altarac et al. 2012). When managing FG patients, this gangrenous tissue requires extensive and repeated debridement (Sallami et al. 2012). Several literatures have shown that patients with diabetes, old age, low blood pressure, high creatine kinase, high lactate, abdominal affection, hemoglobin of less than $10 \mathrm{~g} / \mathrm{dL}$, and platelet count of less

Table 1 There were 19 articles (from January 1, 2009 to December 31, 2013) enrolled into this study

\begin{tabular}{lllllllll}
\hline Duration & Duration [years] & First author & Country & Number & Male \% & Female \% & Mean age & Mortality rate \% \\
\hline $1981 \sim 2010$ & 29 & Martinschek et al. (2012) & Germany & 55 & 61.8 & 38.2 & 48 & 16.4 \\
$1994 \sim 2006$ & 12 & Macro et. al. (2010) & Spain & 51 & 94 & 6 & 63 & 16 \\
$1995 \sim 2010$ & 15 & Sallami et a. (2012) & Tunisia & 40 & NA & NA & 52.8 & 17.5 \\
$1995 \sim 2010$ & 15 & Altarac et al. (2012) & Croatia & 41 & 95 & 5 & 62 & 36.6 \\
$1996 \sim 2006$ & 10 & Yilmazlar et al. (2010) & Turkey & 80 & 71.3 & 28.7 & 57 & 21 \\
$1996 \sim 2006$ & 10 & Ozturk et al. (2011) & Turkey & 44 & 52.3 & 47.7 & 57 & 36.3 \\
$1996 \sim 2008$ & 12 & Czymek et al. (2010) & Germany & 38 & NA & NA & 57.7 & 21.1 \\
$1998 \sim 2006$ & 8 & MEHL et al. (2010) & Brazil & 40 & 77 & 23 & 47.2 & 20 \\
$1999 \sim 2009$ & 10 & Koukouras et al. (2011) & Germany & 45 & 88.9 & 11.1 & 50 & 15.6 \\
$2000 \sim 2008$ & 8 & Malik et al. (2010) & Pakistan & 73 & 91.8 & 8.2 & 57.3 & 17.8 \\
$2000 \sim 2008$ & 8 & Chen et al. (2011) & Taiwan & 50 & NA & NA & 53.6 & 12 \\
$2001 \sim 2004$ & 4 & Sorensen et al. (2009) & USA & 1680 & 97.7 & 2.3 & 50.9 & 7.5 \\
$2001 \sim 2011$ & 10 & Roghmann et al. (2012) & Germany & 44 & NA & NA & 59 & 30 \\
$2002 \sim 2007$ & 5 & Morua et al. (2009) & Mexico & 63 & 96 & 4 & 47.5 & 12 \\
$2002 \sim 2007$ & 5 & Ullah et al. (2009) & Pakistan & 60 & 83.3 & 16.7 & 47 & 7 \\
$2003 \sim 2008$ & 5 & Vargas et al. (2011) & Spain & 42 & 100 & 0 & 51 &
\end{tabular}

The combined data and descriptions of Fournier's gangrene are listed in Table 1. $\mathrm{NA}=$ Not Available. 


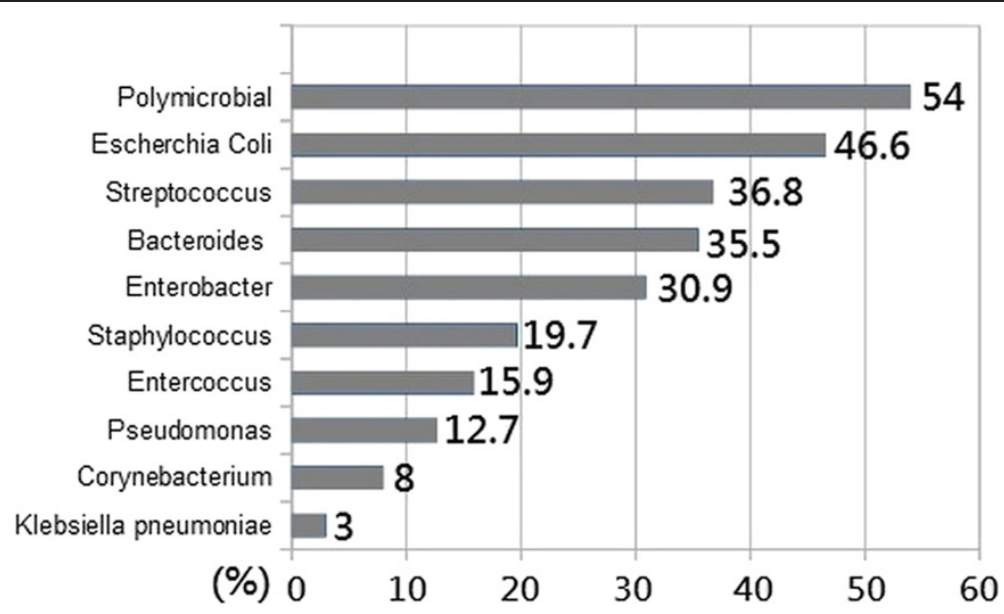

Figure 1 List of commonly found pathogens involving Fournier's gangrene (presented in percentages).

than $150 \times 10^{9} / \mathrm{L}$ are associated with poor outcomes (Martinschek et al. 2012; Ruiz-Tovar et al. 2012).

Many literatures have determined that the risk factors of FG include diabetes mellitus, hypertension, heart disease, smoking, long-term steroid therapy, alcoholism or alcohol abuse, in hot and humid season, and renal failure (Martinschek et al. 2012; Sallami et al. 2012; Czymek et al. 2010; Mehl et al. 2010; Malik et al. 2010; Ullah and Khan 2009). Out of the many risk factors, diabetes mellitus is still the highest influencing factor on FG where $43.7 \%$ of FG patients are diabetic. A report by Czymek et. al. showed that being overweight is also a risk factor of FG, where nearly $40 \%$ of FG patients have body mass indexes (BMIs) of higher than 30 (Czymek et al. 2010; Mehl et al. 2010). Although there are several known risk factors that can lead to the development of FG, the clinical onset of FG is still unpredictable.

The most common symptoms of FG are perineal pain and fever that are accompanied by swelling and reddening of perineum or genital area, and the gangreneous change of overlaying skin (Ruiz-Tovar et al. 2012).

The most common microbiology involved in FG is polymicrobial infection (54\%), and the most common found pathogen isolate is Escherichia coli (46.6\%). Others contributing pathogen are Streptococcal infection, Bacteroides, Enterobacter, Staphylococcus, Enterococcus, Pseudomonas, Corynebacterium, and Klebsiella pneumoniae (Rodríguez Alonso et al. 2000; Czymek et al. 2010; Mehl et al. 2010). Broad-spectrum antibiotic treatment is suggested to adequately cover poly-microbial pathogen, and careful patient monitoring is required to avoid is fungal or hospitalacquired pathogen infection (Bjurlin et al. 2013).

In terms of gender, there was no significant mortality rate that was found between the genders (Ersoz et al. 2012). A study from Spain $(n=51)$ showed that the survivors of FG are 13.5 years younger than those who have died (60 versus 73.5, $p=0.02$ ) (Luján Marco et al. 2010). In a 2012 report from Turkey $(n=52)$, the non-survivors

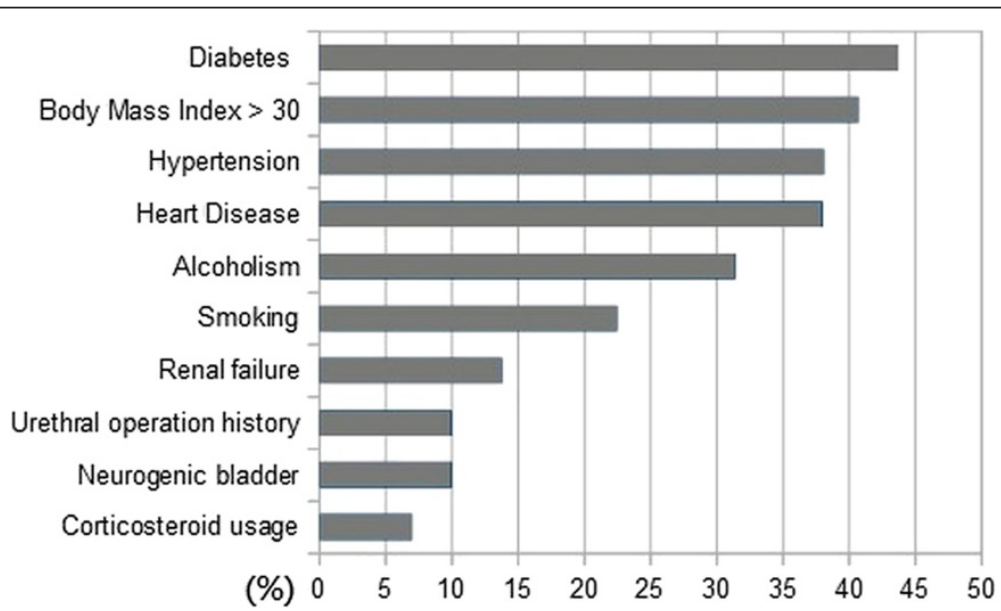

Figure 2 List of commonly found risk factors involving Fournier's gangrene (presented in percentages). 
group are older in age than survivors (62 versus 55 years old]. In our study, the results also showed that the older patients age had higher rates of mortality. This result is concurrent with in the other previous studies, where increased age was shown to be related to higher mortality rate (Martinschek et al. 2012; Roghmann et al. 2012).

Although FG is rare, its rapid progression can lead to life-threatening conditions that require early surgical intervention and parenteral antibiotics to improve patient outcomes (Morua et al. 2009). The mortality rate of FG remains high and ranges from 4.9 to $36.6 \%$ in the recent five years. Due to its high mortality rate and rapid progress, FG must be regarded in clinical settings. The reduction of obesity, alcohol consumption, tobacco use is helpful in reducing the possible risk of FG. Furthermore, older patients with genital or perineal pain should be examined for crepitus dermis. Finally, when a patient is diagnosed with FG, swift consultation with surgeons and administration of broad-spectrum antibiotics are required in order to save the patient's live.

\section{Competing interests}

The authors declare that there is no conflict of interests.

\section{Authors' contribution}

Tang LM: Study Design and Draft writing. Su YJ: Statistical analysis, management and revision. Lai YC: Discussion. All authors read and approved the final manuscript.

\section{Authors' information}

Dr. Lap-Ming Tang and Dr. Yu-Jang Su are senior attending physicians worked at Department of Emergency Medicine, Mackay Memorial Hospital, Taipei 10449, Taiwan. Dr. Yu-Jang Su is also awarded six times of best teacher of Mackay Memorial Hospital, Taipei till 2014, and teaches at department of Oral Hygiene, College of Oral Medicine, Taipei Medical University, Taipei, Taiwan as an Assistant Professor. Dr. Yen-Chun Lai is a professional anesthesiologist working at Department of Anesthesiology, Taiwan Adventist Hospital, Taipei, Taiwan. We all have copious clinical experiences in practice.

\section{Author details}

'Department of Emergency Medicine, Mackay Memorial Hospital, Taipei, Taiwan. ${ }^{2}$ Department of Oral Hygiene, College of Oral Medicine, Taipei Medical University, Taipei, Taiwan. ${ }^{3}$ Department of Anesthesiology, Taiwan Adventist Hospital, Taipei, Taiwan.

Received: 4 November 2014 Accepted: 30 December 2014

Published online: 13 January 2015

\section{References}

Altarac S, Katušin D, Crnica S, Papeš D, Rajković Z, Arslani N (2012) Fournier's gangrene: etiology and outcome analysis of 41 patients. Urol Int 88(3):289-293

Bjurlin MA, O'Grady T, Kim DY, Divakaruni N, Drago A, Blumetti J, Hollowell CM (2013) Causative pathogens, antibiotic sensitivity, resistance patterns, and severity in a contemporary series of Fournier's gangrene. Urology 81(4):752-758

Chen SY, Fu JP, Chen TM, Chen SG (2011) Reconstruction of scrotal and perineal defects in Fournier's gangrene. J Plast Reconstr Aesthet Surg 64(4):528-534

Czymek R, Frank P, Limmer S, Schmidt A, Jungbluth T, Roblick U, Bürk C, Bruch HP, Kujath $P$ (2010) Fournier's gangrene: is the female gender a risk factor? Langenbecks. Arch Surg 395(2):173-180

Ersoz F, Sari S, Arikan S, Altiok M, Bektas H, Adas G, Poyraz B, Ozcan O (2012) Factors affecting mortality in Fournier's gangrene: experience with fifty-two patients. Singapore Med J 53(8):537-540

Göktaş C, Yıldııım M, Horuz R, Faydacı G, Akça O, Cetinel CA (2012) Factors affecting the number of debridements in Fournier's gangrene: our results in 36 cases. Ulus Travma Acil Cerrahi Derg 18(1):43-48
Koukouras D, Kallidonis P, Panagopoulos C, Al-Aown A, Athanasopoulos A, Rigopoulos C, Fokaefs E, Stolzenburg JU, Perimenis P, Liatsikos E (2011) Fournier's gangrene, a urologic and surgical emergency: presentation of a multi-institutional experience with 45 cases. Urol Int 86(2):167-172

Luján Marco S, Budía A, Di Capua C, Broseta E, Jiménez CF (2010) Evaluation of a severity score to predict the prognosis of Fournier's gangrene. BJU Int 106(3):373-376

Malik AM, Sheikh S, Pathan R, Khan A, Sheikh U (2010) The spectrum of presentation and management of Fournier's gangrene-an experience of 73 cases. J Pak Med Assoc 60(8):617-619

Martinschek A, Evers B, Lampl L, Gerngroß H, Schmidt R, Sparwasser C (2012) Prognostic aspects, survival rate, and predisposing risk factors in patients with Fournier's gangrene and necrotizing soft tissue infections: evaluation of clinical outcome of 55 patients. Urol Int 89(2):173-179

Mehl AA, Nogueira Filho DC, Mantovani LM, Grippa MM, Berger R, Krauss D, Ribas $D$ (2010) Management of Fournier's gangrene: experience of a university hospital of Curitiba. Rev Col Bras Cir 37(6):435-441

Montoya Chinchilla R, Izquierdo Morejon E, Nicolae Pietricicâ B, Pellicer Franco E, Aguayo Albasini JL, Miñana LB (2009) Fournier's gangrene. Descriptive analysis of 20 cases and literature review. Actas Urol Esp 33(8):873-880

Morua AG, Lopez JA, Garcia JD, Montelongo RM, Guerra LS (2009) Fournier's gangrene: our experience in 5 years, bibliographic review and assessment of the Fournier's gangrene severity index. Arch Esp Urol 62(7):532-540

Ozturk E, Sonmez Y, Yilmazlar T (2011) What are the indications for a stoma in Fournier's gangrene? Colorectal Dis 13(9):1044-1047

Rodríguez Alonso A, Pérez García MD, Núñez López A, Ojea Calvo A, Alonso Rodrigo A, Rodríguez Iglesias B, Barros Rodríguez JM, Benavente Delgado J, Nogueira March JL (2000) Fournier's gangrene: anatomo-clinical features in adults and children. Therapy update Actas Urol Esp 24(4):294-306

Roghmann F, von Bodman C, Löppenberg B, Hinkel A, Palisaar J, Noldus J (2012) Is there a need for the Fournier's gangrene severity index? Comparison of scoring systems for outcome prediction in patients with Fournier's gangrene. BJU Int 110(9):1359-1365

Ruiz-Tovar J, Córdoba L, Devesa JM (2012) Prognostic factors in Fournier gangrene. Asian J Surg 35(1):37-41

Sallami S, Maalla R, Gammoudi A, Ben Jdidia G, Tarhouni L, Horchani A (2012) Fournier's gangrene: what are the prognostic factors? Our experience with 40 patients. Tunis Med 90(10):708-714

Shyam DC, Rapsang AG (2013) Fournier's gangrene. Surgeon 11(4):222-232

Sorensen MD, Krieger JN, Rivara FP, Broghammer JA, Klein MB, Mack CD, Wessells H (2009) Fournier's Gangrene: population based epidemiology and outcomes. J Urol 181(5):2120-2126

Ullah S, Khan M, Asad Ullah Jan M (2009) Fournier's gangrene: a dreadful disease. Surgeon 7(3):138-142

Vargas AH, Carbonell J, Osorio D, García HA (2011) Evaluation of Fournier's necrosis in a high complexity hospital. Arch Esp Urol 64(10):948-952

Yilmazlar T, Ozturk E, Ozguc H, Ercan I, Vuruskan H, Oktay B (2010) Fournier's gangrene: an analysis of 80 patients and a novel scoring system. Tech Coloproctol 14(3):217-223

\section{Submit your manuscript to a SpringerOpen ${ }^{\odot}$ journal and benefit from:}

- Convenient online submission

Rigorous peer review

- Immediate publication on acceptance

- Open access: articles freely available online

- High visibility within the field

- Retaining the copyright to your article

Submit your next manuscript at $>$ springeropen.com 